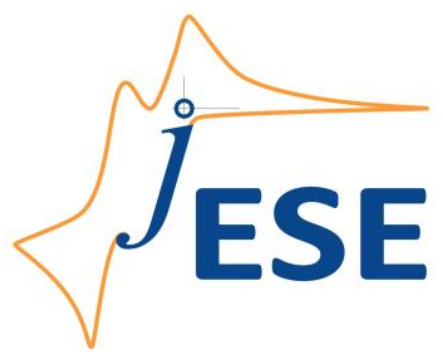

Open Access : : ISSN 1847-9286

www.jESE-online.org

Original scientific paper

\title{
Cerium oxide as conversion coating for the corrosion protection of aluminum
}

JELENA GULICOVSKI ${ }^{\bowtie}$, JELENA BAJAT*, VESNA MIŠKOVIĆ-STANKOVIĆ*, BOJAN JOKIĆ*, VLADIMIR PANIĆ**, SLOBODAN MILONJIĆ

Vinča Institute of Nuclear Sciences, University of Belgrade, P. O. Box 522, 11000 Belgrade, Serbia

*Faculty of Technology and Metallurgy, University of Belgrade, Karnegijeva 4, 11120 Belgrade, Serbia

**ICTM - Center of Electrochemistry, University of Belgrade, Njegoševa 12, 11000 Belgrade, Serbia

Corresponding Author: E-mail: rocenj@vinca.rs; Tel.: +381-11-3408-865; Fax: +381-11-3408-224

Received: August 9, 2013; Published: Novembar 09, 2013

\begin{abstract}
$\mathrm{CeO}_{2}$ coatings were formed on the aluminum after Al surface preparation, by dripping the ceria sol, previously prepared by forced hydrolysis of $\mathrm{Ce}\left(\mathrm{NO}_{3}\right)_{4}$. The anticorrosive properties of ceria coatings were investigated by the electrochemical impedance spectroscopy (EIS) during the exposure to $0.03 \% \mathrm{NaCl}$. The morphology of the coatings was examined by the scanning electron microscopy (SEM). EIS data indicated considerably larger corrosion resistance of $\mathrm{CeO}_{2}$-coated aluminum than for bare Al. The corrosion processes on $\mathrm{Al}$ below $\mathrm{CeO}_{2}$ coating are subjected to more pronounced diffusion limitations in comparison to the processes below passive aluminum oxide film, as the consequence of the formation of highly compact protective coating. The results show that the deposition of ceria coatings is an effective way to improve corrosion resistance for aluminum.
\end{abstract}

Keywords

Ceria, Coatings, Corrosion, Microstructure.

\section{Introduction}

It is well known that chromate-based chemical conversions were used for corrosion protection of aluminum for decades. On the other hand, because of toxic and carcinogenic properties of chromium, this kind of coatings should be soon withdrawn from all industrial processes $[1,2]$. 
Many researchers tried to find alternative for chromate conversions; it is believed that rare earth elements (cerium, lanthanum, neodymium and yttrium) could effectively inhibit the corrosion of aluminum. Hinton et al. [3,4] introduced the application of lanthanide compounds for this purpose. The reported results showed that these barrier coatings simply prevent contact between aluminum surface and corrosive species. The best degree of corrosion inhibition is achieved with cerium [5-8].

Based on these findings, the aim of this study was to examine efficacy of ceria based coating for corrosion protection of aluminum, by means of the scanning electron microscopy (SEM) and the electrochemical impedance spectroscopy (EIS).

\section{Experimental}

\section{Materials}

The aluminum panels, $20 \mathrm{~mm} \times 18 \mathrm{~mm} \times 1 \mathrm{~mm}$ in size, were used as substrates. The surface of specimens was mechanically polished by $800,1200,2400$ and 4000 grit emery papers. To remove the surface contamination the panels were degreased in alkaline solution containing: $\mathrm{NaOH}$, $\mathrm{Na}_{3} \mathrm{PO}_{4} \cdot 12 \mathrm{H}_{2} \mathrm{O}, \mathrm{Na}_{2} \mathrm{SiO}_{3}$ and ethoxylate of nonylphenol with nine molecules of ethylene oxide, during $1 \mathrm{~min}$ at $70{ }^{\circ} \mathrm{C}$. Finally, the panels were rinsed by distilled water and dried in air at room temperature.

For the investigation in this study ceria sol which was obtained by forced hydrolysis of $1 \mathrm{~N}$ $\mathrm{Ce}\left(\mathrm{NO}_{3}\right)_{4}$ aqueous solution was used. The ceria sol was synthesized by Gulicovski et al. [9] according to the reported procedure. The main characteristics of the synthesized ceria sol are: $\mathrm{pH}$ value of synthesized sol, 0.66 , average particle size, $71 \mathrm{~nm}$, and solid phase content, $0.51 \mathrm{mass} \%$. In order to obtain the stable and pure ceria dispersion, nitrates were removed from the prepared sol by ultrafiltration. The final $\mathrm{pH}$ of the sol was around 4 .

The $\mathrm{CeO}_{2}$ coatings were formed on the aluminum panels by dripping method. The ceria sol was applied in the quantity of $2 \times 30 \mu \mathrm{l}$. Between the two applications, dispersing medium was evaporated at $35^{\circ} \mathrm{C}$.

\section{Methods}

The corrosion behavior of the ceria-coated aluminum was determined by the electrochemical impedance spectroscopy (EIS). EIS data were recorded at the open circuit potential using a Gamry, Reference 600 potentiostat/galvanostat/ZRA.

To examine the surface morphology of the coatings, scanning electron microscope (SEM) JOEL, model JSM-5800, at $20 \mathrm{kV}$ was used.

\section{Results and Discussion}

\section{Surface morphology of bare $\mathrm{Al}$ and $\mathrm{Al} / \mathrm{CeO}_{2}$}

Figure 1 shows typical SEM images of the $\mathrm{Al}$ and $\mathrm{Al} / \mathrm{CeO}_{2}$ specimens before and after prolonged exposure to $0.03 \% \mathrm{NaCl}$ solution. An uniform pattern of the Al surface can be seen after mechanical polishing and degreasing (Figs. 1a and 1b). A highly porous film consisted of uniform $\mu \mathrm{m}$-sized grains is observed at the Al surface after immersion in $\mathrm{NaCl}$ solution (Figs. $1 \mathrm{c}$ and $1 \mathrm{~d}$ ), i.e., native homogeneous surface has been destroyed and a new layer of corrosion products was produced. 

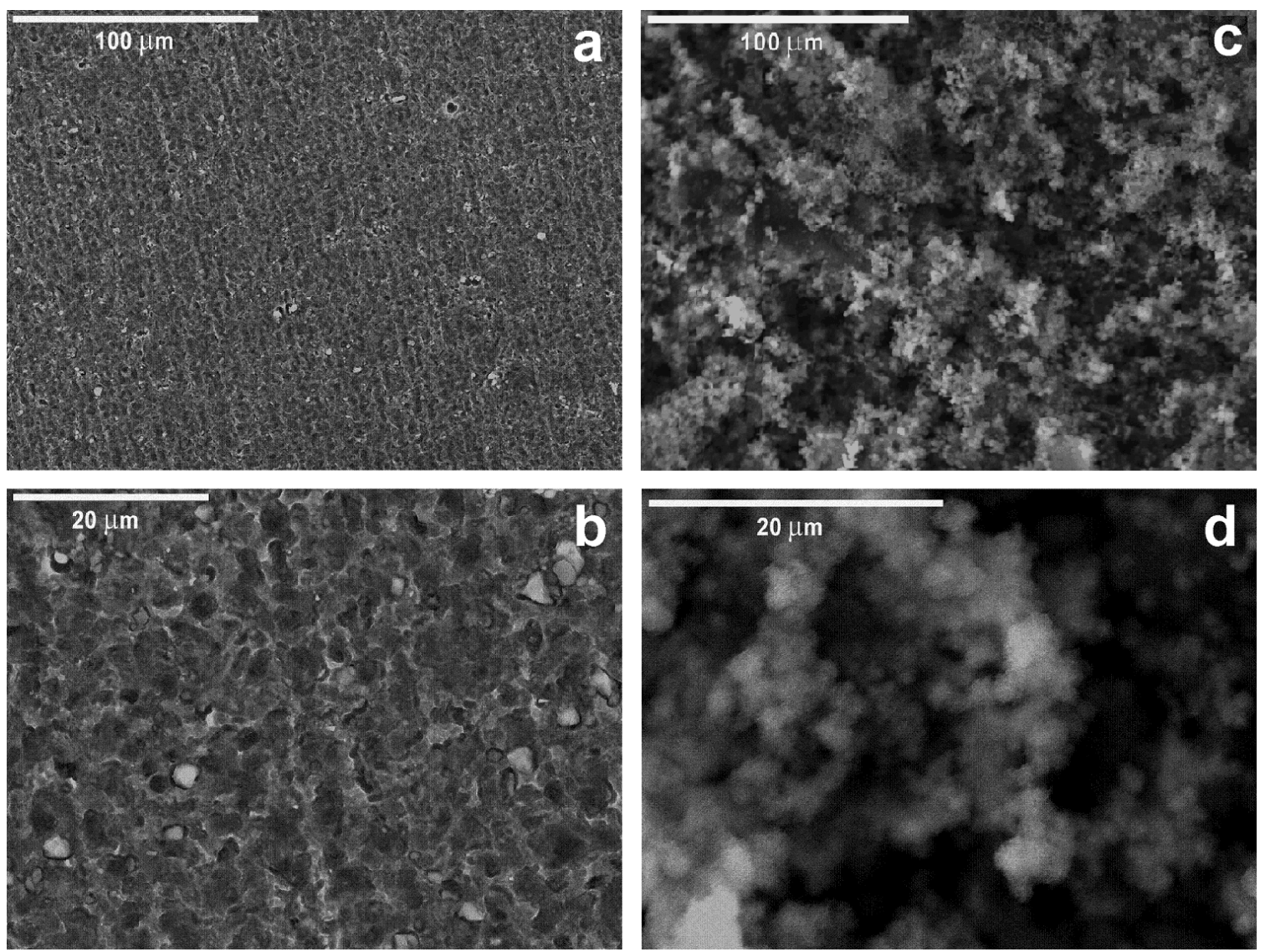

Figure 1. Typical scanning electron micrographs of $A /$ sample at two different magnifications: before ( $a$ and $b$ ) and after exposure to $0.03 \% \mathrm{NaCl}(c$ and $d)$.

Typical surface morphology of a cerium oxide coating deposited onto Al panel is shown in Fig. 2. Narrow cracks and sparing pits are visible (Figs. $2 a$ and $2 b$ ); however, no signs of the peeling were detected. The cracks are typical for rather thick conversion film and it is the result of the stress induced in the film during the drying process. SEM micrographs of the film surface after immersion in $0.03 \% \mathrm{NaCl}$ solution (Figs. $2 \mathrm{c}$ and $2 \mathrm{~d}$ ) revealed presence of agglomerates of corrosion products (Fig. 2c). The agglomerates appear to lay over compact granular structure (Fig. 2d), uniformly consisted of $\mu \mathrm{m}$-sized fluffy grains.

\section{Corrosion behavior}

The corrosion behavior and stability of prepared $\mathrm{Al} / \mathrm{CeO}_{2}$ sample were investigated by EIS after different times of the exposure to $0.03 \% \mathrm{NaCl}$. The data registered after $24 \mathrm{~h}$ of exposure are shown in Fig. 3 as complex plane and Bode phase shift spectra and compared to the data of $\mathrm{Al}$ reference sample. The complex plane spectra are consisted of at least three semicircles. The semicircle at lowest frequencies (below $0.4 \mathrm{~Hz}$ ) is more pronounced for $\mathrm{Al} / \mathrm{CeO}_{2}$, whereas it is only weakly indicated in the spectrum of Al (below $0.3 \mathrm{~Hz}$ ). The peaks corresponding to two the high frequency semicircles appear clearly in the phase shift spectra, whereas low frequency semicircle can be observed only as a shoulder around $0.1 \mathrm{~Hz}$ for $\mathrm{Al} / \mathrm{CeO}_{2}$. However, phase shifts at low frequencies for both $\mathrm{Al} / \mathrm{CeO}_{2}$ and $\mathrm{Al}$ are similar, around $20^{\circ}$. The semicircles are larger for $\mathrm{Al} / \mathrm{CeO}_{2}$, especially two of them appearing at lower frequencies. This indicates good corrosion protection of the applied ceria coating, since this kind of the spectra, usually observed for the corrosion of aluminum, are assigned to the passive Al-oxide film (high frequency data) and corrosion-related charge transfer processes beneath (low frequency data) [10-12]. 

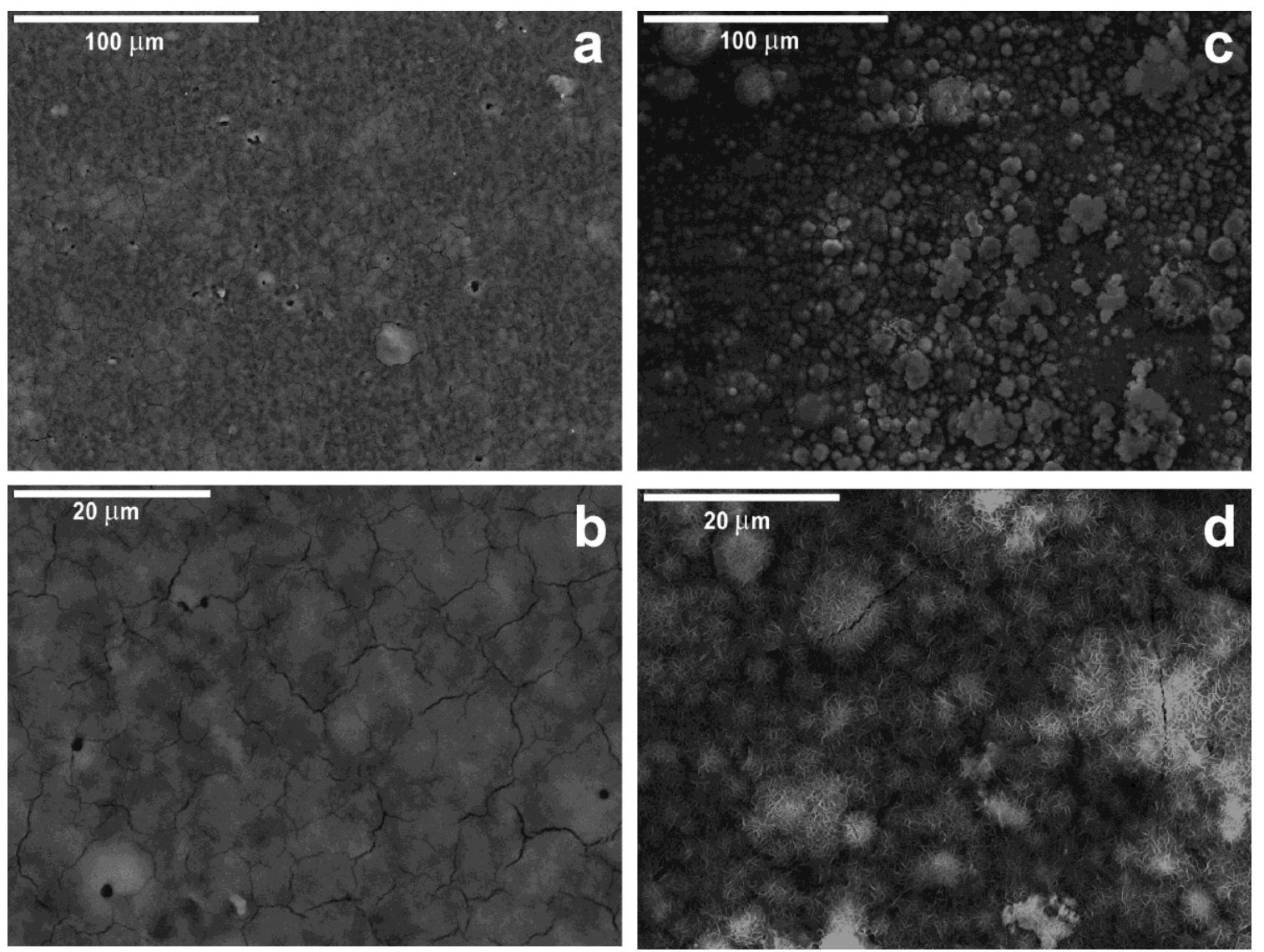

Figure 2. Typical scanning electron macrographs of $\mathrm{Al} / \mathrm{CeO}_{2}$ sample at two different magnifications: before ( $a$ and $b$ ) and after exposure to $0.03 \% \mathrm{NaCl}$ ( $c$ and $d$ ).
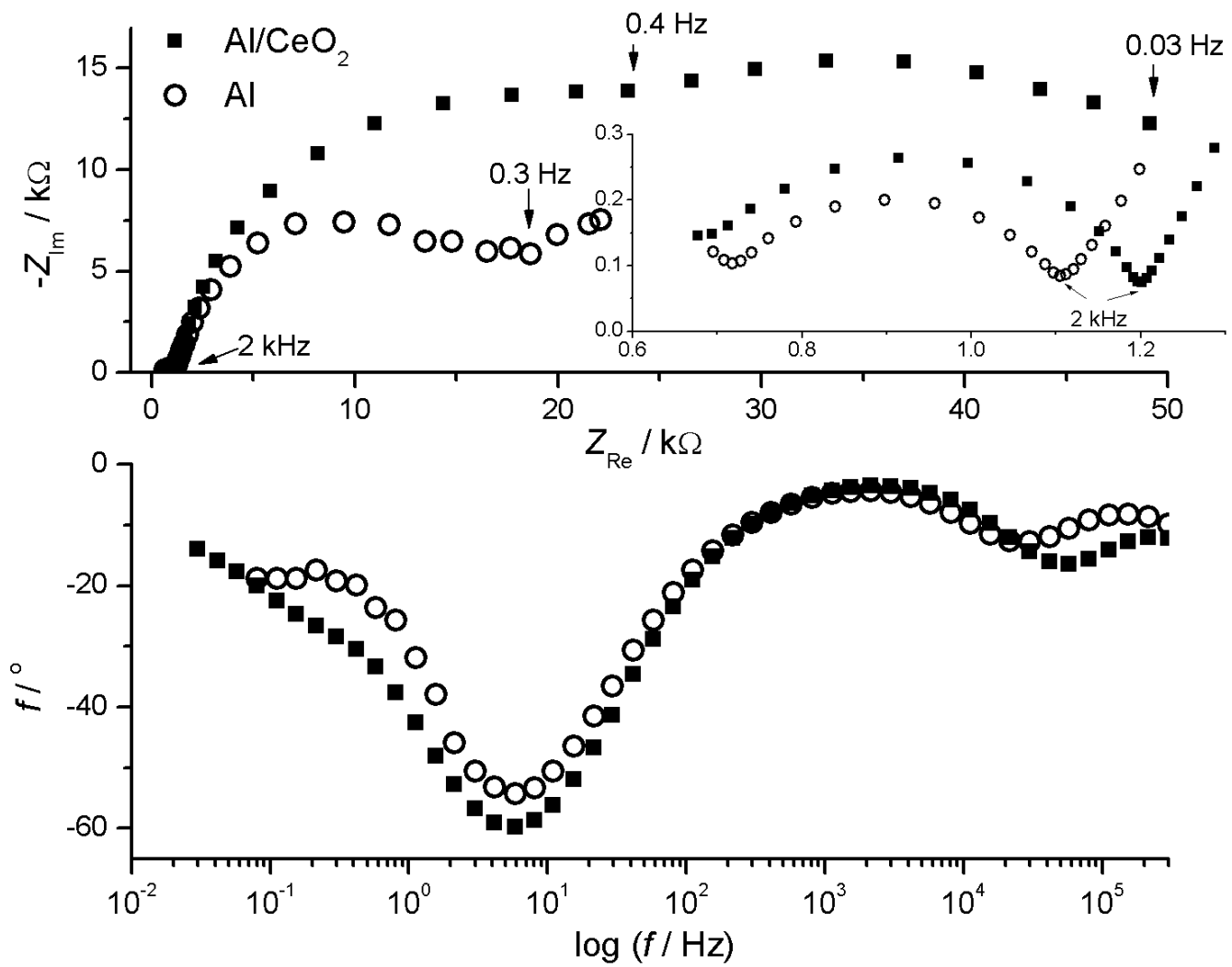

Figure 3. Complex plane and Bode plots of $\mathrm{Al}$ and $\mathrm{Al} / \mathrm{CeO}_{2}$ sample registered at open circuit potential after $24 \mathrm{~h}$ exposure to $0.03 \% \mathrm{NaCl}$. Inset: high frequency parts of the complex plane spectra. 
In order to examine the effect of exposure time on the characteristic features of the EIS spectra, they were recorded at prolonged exposure times. Typical complex plain and Bode plots of EIS data are presented in Fig. 4 by those registered after $312 \mathrm{~h}$ of exposure.

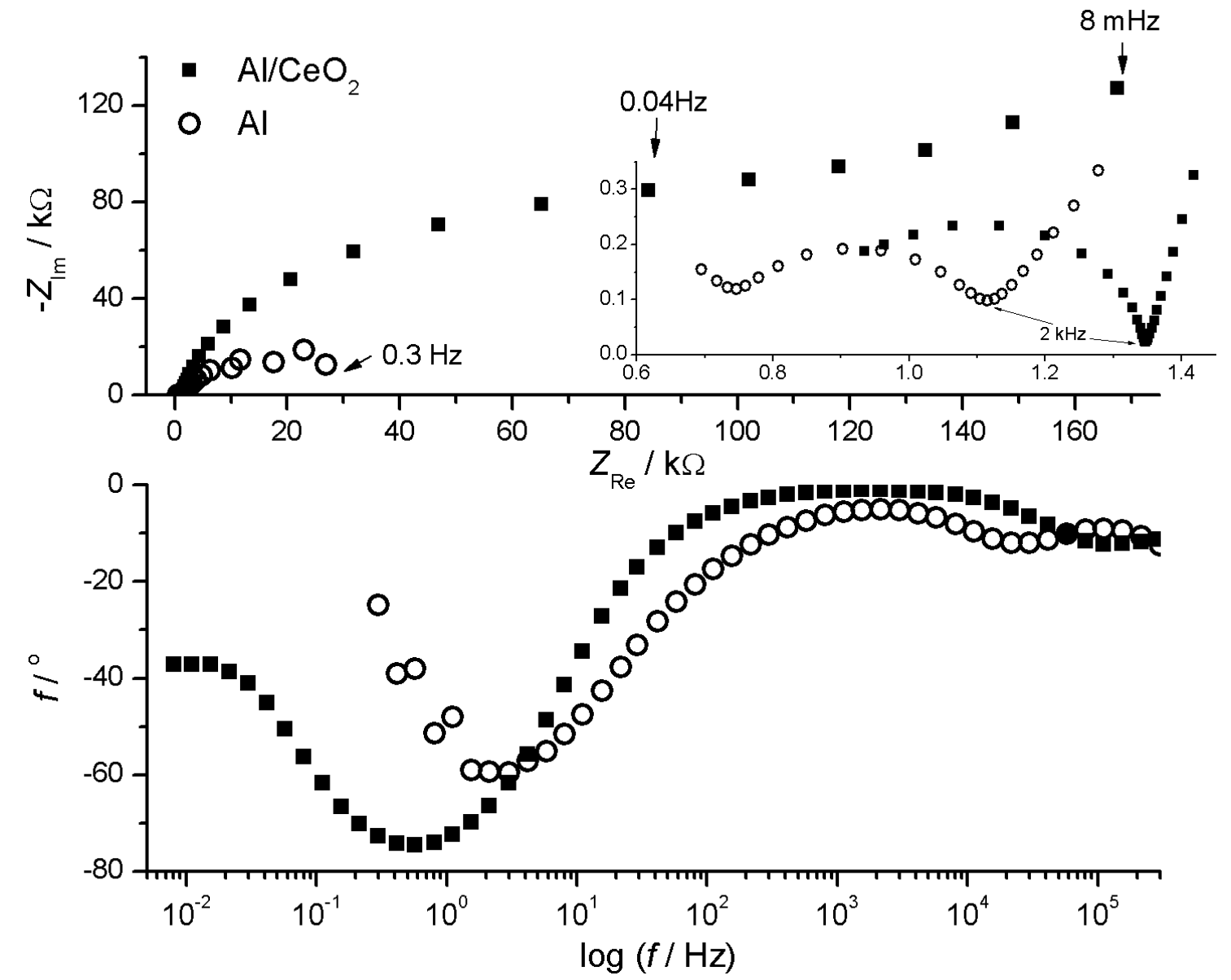

Figure 4. Complex plane and Bode plots of $\mathrm{Al}$ and $\mathrm{Al} / \mathrm{CeO}_{2}$ sample registered at open circuit potential after $312 \mathrm{~h}$ exposure to $0.03 \% \mathrm{NaCl}$. Inset: high frequency parts of the complex plane spectra.

As Fig. 4 shows, prolonged exposure to the corrosive environment does not considerably change the characteristic features of the spectra. The comparison of Figs. 3 and 4 reveals that the spectra for both $\mathrm{Al}$ and $\mathrm{Al} / \mathrm{CeO}_{2}$ samples at high frequencies are poorly affected by the prolongation of the exposure, which indicates that $24 \mathrm{~h}$ of exposure is sufficiently long to allow complete formation of passive oxide layer. However, it appears that corrosion processes on bare $\mathrm{Al}$ are not hindered since its spectra from Figs. 3 and 4 at lower frequencies, related to the charge transfer, are similar. It follows that corrosion products formed after $24 \mathrm{~h}$ are not incorporated into the passive film with impedance response at high frequencies.

These observations, except those related to the high frequency semicircles and passive aluminum-oxide interlayer does not hold for $\mathrm{Al} / \mathrm{CeO}_{2}$ sample. It is to be noted from Figs. 3 and 4 that the semicircles for $\mathrm{Al} / \mathrm{CeO}_{2}$ sample in low frequency domain grow considerably upon the increase in exposure time, which can be considered as a result of increased corrosion resistance with respect to bare Al. At lowest frequencies (below $0.04 \mathrm{~Hz}$ ), the semicircle in Fig. 4 is followed by a straight line assignable to the diffusion controlled corrosion processes. Indeed, the corresponding Bode plot reaches the values around $40^{\circ}$, which is quite close to the theoretical value of $45^{\circ}$. Well pronounced diffusion limitations are due to the presence of a compact protective film induced by $\mathrm{CeO}_{2}$. 


\section{Conclusions}

With an appropriate surface pre-treatment, ceria was formed on the aluminum panels by dripping method. These substrates were characterized by SEM and EIS methods in order to study their possible applications as protective barriers in corrosive environment.

SEM analysis confirmed formation of the oxide film on $\mathrm{Al}$ and $\mathrm{Al} / \mathrm{CeO}_{2}$ substrates after immersion in $0.03 \% \mathrm{NaCl}$ solution. The film is consisted of $\mathrm{Al}_{2} \mathrm{O}_{3}$ agglomerates with compact granular structure that improve corrosion resistance of the ceria coatings.

The results achieved by EIS measurements show that the semicircles obtained for $\mathrm{Al} / \mathrm{CeO}_{2}$ sample in low frequency domain grow considerably upon the increase in exposure in $\mathrm{NaCl}$, which can be considered as a result of increased corrosion resistance with respect to bare Al.

It can be concluded that deposition of ceria coating is an effective way to improve corrosion resistance for aluminum.

Acknowledgement: This work was financially supported by the Ministry of Education, Science and Technological Development of the Republic of Serbia (Project number: 45012)

\section{References}

[1] S.H. Abdel, Surface Coatings Tech. 200 (2006) 3786-3792.

[2] J. Bieber, Mater. Lett. 105 (2007) 425-435.

[3] B.R.W. Hinton, D.R. Arnott, N.E. Ryan, Metals Forum 7 (1984) 211-217.

[4] B.R.W. Hinton, D.R. Arnott, N.E. Ryan, Metals Forum 9 (1986) 162-173.

[5] G.F. William, M.J. O'Keefe, H. Zhou, J.T. Grant, Surface Coatings Tech. 155 (2002) 208-213.

[6] A. Decroly, J.P. Petitjean, Surface Coatings Tech. 194 (2005) 1-9.

[7] P. Campestrini, H. Terryn, A. Hovestad, J.H.W. de Wit, Surface Coatings Tech. 176 (2004) 365-381.

[8] M.A. Dominguez-Crespo, A.M. Torres-Huerta, S.E., Rodil, E. Ramirez-Meneses, G.G. SuarezVelazquez, M.A. Hernandez-Perez, Electrochim. Acta 55 (2009) 498-503.

[9] J.J. Gulicovski, S.K., Milonjić, K. Meszaros Szecsenyi, K., Mater. Manufacturing Proc. 24 (2009) 1080-1085.

[10] M. Metikoš-Huković, R. Babić, Z. Grubač, J. Appl. Electrochem. 32 (2002) 35-41.

[11] C.M.A. Brett, J. Appl. Electrochem. 20 (1990)1000-1003.

[12] F.H. Cao, Z. Zhang, J.F. Li, Y.L. Cheng, J.Q. Zhang, C.N. Cao, Mater. Corros. 55 (2004) 18-23.

(C) 2013 by the authors; licensee IAPC, Zagreb, Croatia. This article is an open-access article distributed under the terms and conditions of the Creative Commons Attribution license (http://creativecommons.org/licenses/by/3.0/) (cc) $\mathrm{Er}$ 